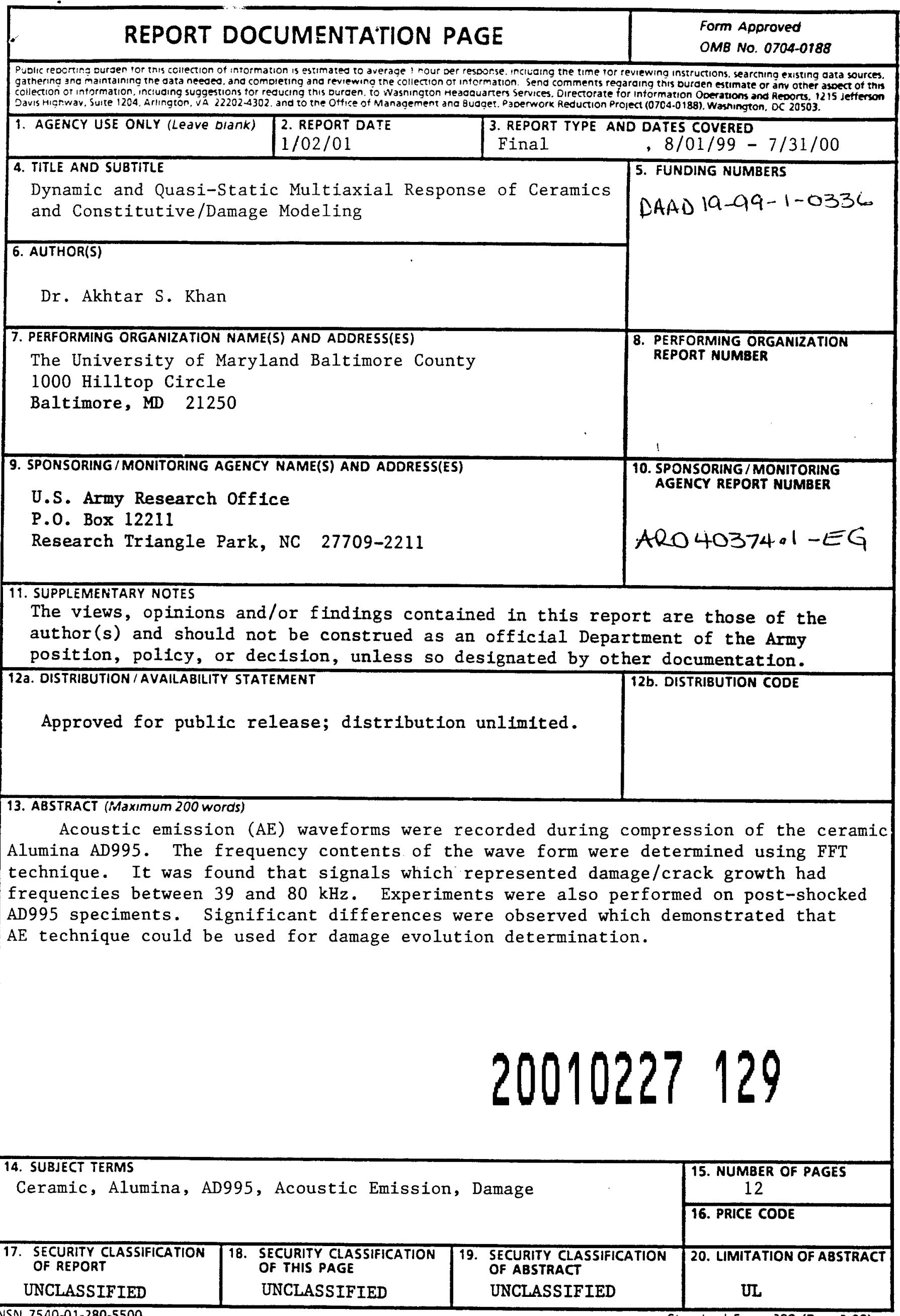




\section{MEMORANDUM OF TRANSMITTAL}

\section{U.S. Army Research Office}

ATTN: AMSRL-RO-RI (Hall)

P.O. Box 12211

Research Triangle Park, NC 27709-2211

Reprint (Orig + 2 copies)

Manuscript (l copy)
Technical Report (Orig + 2 copies)

\ Final Progress Report (Orig + 2 copies)

Related Materials, Abstracts, Theses ( 1 copy)

CONTRACT/GRANT NUMBER: DAAD 19-99-1-0336

REPORT TITLE: Dynamic and Quasi-Static

Multi Axial Response of Ceramics and Constitutive/Damage Modeling is forwarded for your information.

SUBMITTED FOR PUBLICATION TO (applicable only if report is manuscript):

DO NOT REAOVE LABEL BEILOW

FOR IDENTIFICATION PURPOSES

Dr. Akhtar S. Khan 40374-EG University of Maryland-Baltimore County Dept. of Mechanical Engineering Baltimore, MD 21250
Sincerely,

Aknter S. Khen

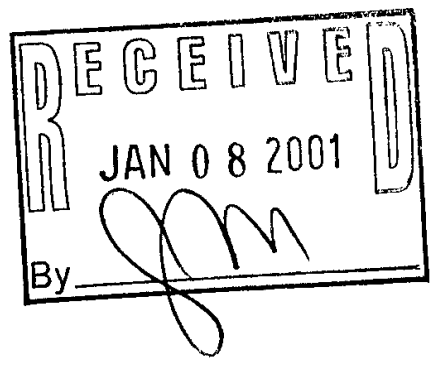




\title{
DYNAMIC AND QUASI-STATIC MULTI-AXIAL RESPONSE OF CERAMICS AND CONSTITUTIVE/DAMAGE MODELING
}

Final Progress Report

$(8 / 01 / 99-7 / 31 / 00)$

\author{
By \\ Akhtar S. Khan
}

January 2, 2001

U.S. Army Research Office

Grant No: DAAD19-99-1-0336

The University of Maryland Baltimore County

1000 Hilltop Circle

Baltimore, MD 21250

APPROVED FOR PUBLIC RELEASE; DISTRIBUTION UNLIMITED

THE VIEWS, OPINIONS, AND /OR FINDINGS CONTAINED IN THIS REPORT ARE THOSE OF THE AUTHOR(S) AND SHOULD NOT BE CONSTRUED AS AN OFFICIAL DEPARTMENT OF THE ARMY POSITION, POLICY, OR DECISION, UNLESS SO DESIGNATED BY OTHER DOCUMENTATION 


\section{DYNAMIC AND QUASI-STATIC MULTI-AXIAL RESPONSE OF}

\section{CERAMICS AND CONSTITUTIVE/DAMAGE MODELING}

\section{INTRODUCTION:}

Ceramics have drawn considerable interest in past two decades $(4,6,8,13,14,17$, $18,19,20)$ due to its premise for possible use as armor material. An accurate response description of ceramics, in terms of a constitutive/damage model, is essential in any numerical code to determine behaviors in terms of integrity of a ceramic structure during low to high velocity impact. An important aspect of constitutive/damage modeling is to connect macroscopic response to actual microscopic damage in the material during loading. The conventional techniques of radiography, scanning and transmission electron microscopy are less preferable to determine increasing damage and its quantification during loading, than a continuous damage monitoring technique. Acoustic emission technique has the potential of monitoring damage during loading.

Acoustic emission has been used to inspect compressed gas cylinders (1), to monitor damage in composite materials (3), to determine damage in aircraft structures (15), and to find critical crack size in ceramics (16). Other relevant studies in acoustic emission concern with source characterization (5), using neural network to solve acoustic emission problems (7), providing calibration technique for acoustic emission (9), outlining sensor selection and problems (10), and determining theoretical basis for acoustic emission (11). The acoustic emission methodologies can be divided in two major groups. The classical approach is primarily based on number of acoustic emission which are larger than a pre-determined threshold value. The modern wave-form technique consist of recording each acoustic emission wave and determining a frequency content of each wave using Fast Fourier Transform (FFT) technique. Using this technique, we have been able to identify different failure modes in composites (3).

Several experimental and numerical studies have been performed on ceramics ( 2 , $4,6,8,13,20$ ). However, none of them are related to continuous monitoring of damage, which can facilitate in the development of constitutive/damage models, or refinement of existing models. Significant damage models, which have been developed for ceramics and similar materials, include a micro-mechanical damage model (12), Rajendran-Grove model $(17,19)$, and Johnson-Holmquist ceramic model (18). The latter two seem specially suitable for ceramics and a comparison of the two models are given in (18). In these models, an initial isotropic crack density and size are assumed to make prediction for comparison with the experimental results. It is the objective of this study to explore the use of acoustic emission wave frequency analysis to monitor continuous evolution of damage in the ceramic materials. 


\section{EXPERIMENTAL PROCEDURES:}

The experimental arrangement is shown in Figure 1. In this study, almost cubical specimens of Alumina AD 995 were compressed in a Material Test System (MTS 809). The test samples were approximately 0.3 inch by 0.3 inch, and 0.3 inch in height. The top and bottom surfaces were lubricated by using Teflon sheets. The Acoustic Emission transducer was mounted on a flattened surface of the top grip, just adjacent to the test sample. A thin layer of grease was used between the transducer and the flat surface of the grip to ensure good coupling between the two surfaces. The compression experiments were performed either at a constant displacement rate of 0.6 microns per second, or at a constant load rate of $0.8 \mathrm{lbs}$. per second.

A F4012 Fracture Wave Detector, manufactured by the Digital Wave Corp., was employed in this investigation. The acoustic emission equipment was designed to capture waveforms of wide bandwidth at high speeds and with ultra-high fidelity. The Fracture Wave Detector system consisted of the following components.

\section{Broadband Transducers}

These were piezoelectric transducers which were displacement sensitive and of high fidelity. The operational frequency range was from $50 \mathrm{kHz}$ to $1.5 \mathrm{MHz}$. A disc shaped piezoelectric crystal was backed by damping material and placed in a cylindrical housing measuring 0.25 inch in diameter and 0.5 inch in height. The output signal of this transducer was typically between 10 micro-volts and 10 milli-volts.

\section{Broadband Pre-amplifiers}

These devices amplified the signal from the transducer to normal working range of the instrumentation to facilitate the signal to travel without being lost in noise to the signal conditioning module. The pre-amplifiers had two gain levels namely, $20 \mathrm{~dB}$ (x10) and $40 \mathrm{~dB}$ (x20). The working impedance of the circuit was $50 \mathrm{Ohms}$.

\section{Signal Conditioning Module with Power Source}

Each signal conditioning module (SCM) monitored one transducer independent of the other. Each channel of pre-amplifier was powered independently by the SCM; it controlled the filtering of the input and triggering signals, the trigger threshold level and the echo delay time. The higin pass filter attenuated frequencies below its set value which was $0.1 \mathrm{MHz}$. The low pass filter attenuated frequencies above its set value of $0.5 \mathrm{MHz}$. The threshold value was the voltage which defined an event and was set at 0.03 Volts. The echo delay time was the length of time from the trigger signal until the Analog-toDigital boards would rearm and a new event could be captured. This can be set from 100 micro-seconds to 100 milli-seconds and was very useful for avoiding reflections. In these experiments a value of 300 micro-seconds was used. 


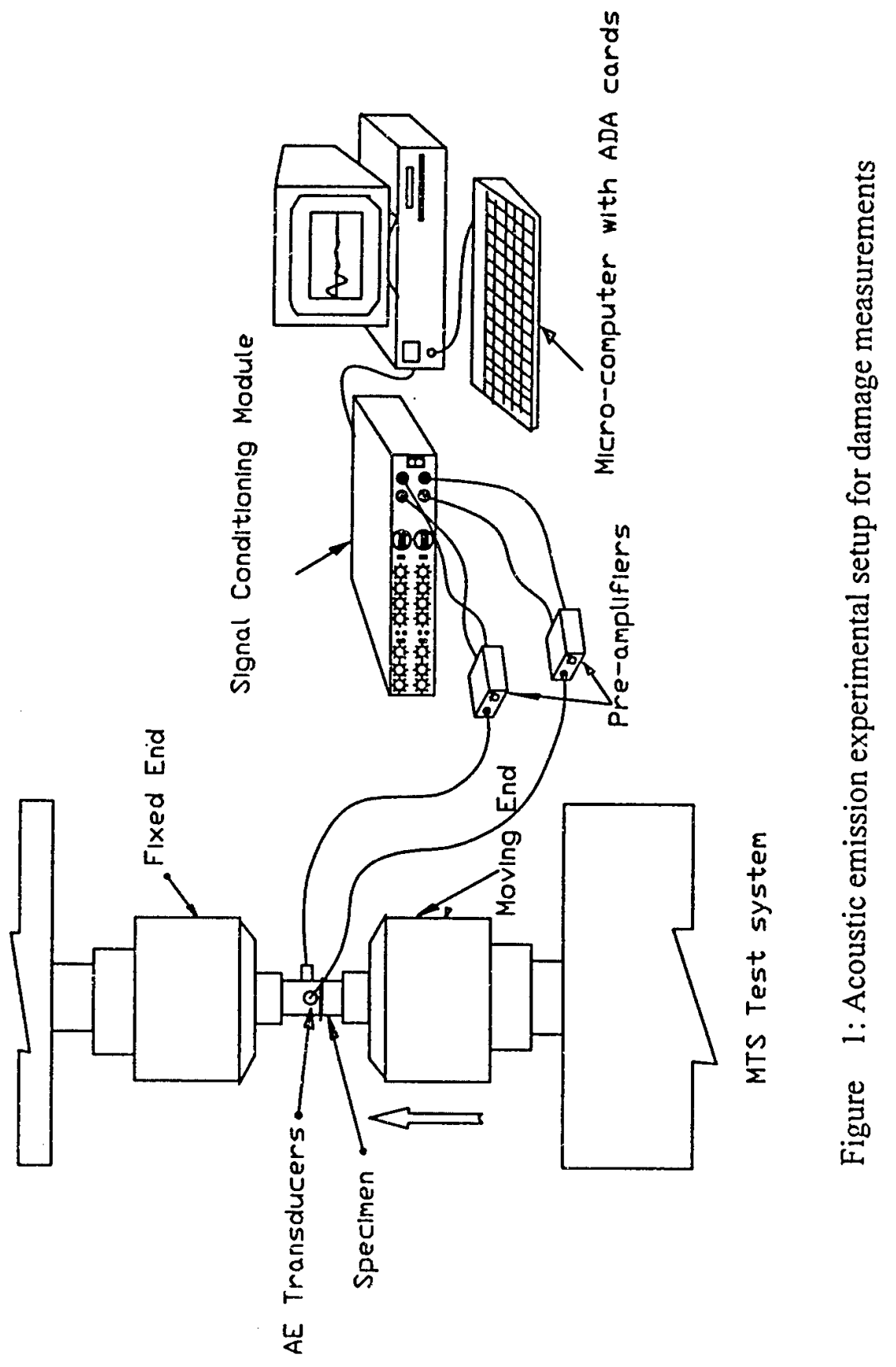




\section{Data Acquisition and System Software}

The Fracture Wave Detector system was designed for the acquisition and analysis of broadband $\mathrm{AE}$ signal waveforms. $\mathrm{AE}$ waveforms were captured and stored digitally. The system was rated at $35 \mathrm{MHz}$ and $\mathrm{A} / \mathrm{D}$ conversion was at 12 bit. Acquisition parameters such as digitization rate, number of points per waveform and pre-trigger level could be set from the data acquisition module. The post-test analysis module provided the means to view stored waveforms and perform digital processing on these signals. Fast Fourier Transform (FFT) technique was applied to the digitized waveforms and the amplitude spectra of the waves were displayed. The plots of event versus time were also analyzed.

\section{EXPERIMENTAL RESULTS AND DISCUSSION:}

Figure 2 contains the acoustic emission events as a function of stress in the material. It contains two plots, one for the experiment at a constant displacement of 0.6 microns per second (C1), while the other is for a test at a constant loading rate of $0.8 \mathrm{lb}$ per second (C2). It appears that in constant load rate more acoustic emissions are captured. This may be due to the reason that in the constant displacement rate experiment, some acoustic emission signals may be lost if additional signals were emitted before the system rearmed itself. In the final stages of damage evolution, the acoustic emission is much faster if a constant displacement rate is prescribed than if the experiment is performed in a constant load rate mode. Each event was captured as an wave arriving at the transducer location. Each wave was analyzed for frequency contents using the FFT software. In order to save space, the amplitude versus frequency of each wave was grouped in four stress ranges. These four plots are shown in Figure 3 for the displacement rate controlled experiment. These results are for 'as-received' material. In 0 to $200 \mathrm{ksi}$ range, the pre-existing cracks do not grow. Almost all acoustic emission is very low frequency noise. In the following higher stress range, the pre-existing cracks grow in size causing additional damage in the material at two predominant frequencies, one around $80 \mathrm{kHz}$ and the other around $250 \mathrm{kHz}$. Subsequently, all damage evolution appear to be between 39 and $78 \mathrm{kHz}$.

Figure 4 contains the grouped frequency contents of acoustic emission in the load rate controlled experiment. Similar conclusions may be drawn as in the case of the previous figure. In Figure 5, the acoustic events are shown as a function of stress in Alumina AD 995 specimen which was subjected to a shock loading under a plate impact experiment. The results in this case are quite different than in the previous un-shocked samples. The acoustic emission signals start at much lower stress as the material is more damaged in this case, i.e. the number and size of the cracks are much larger and therefore they extend at much lower stress. The event numbers are also much larger than previous two cases. The frequency contents, grouped in five stress ranges are shown in Figure 6. Again, the frequency contents of the acoustic emission are in the same range of 39 to 80 $\mathrm{kHz}$. 


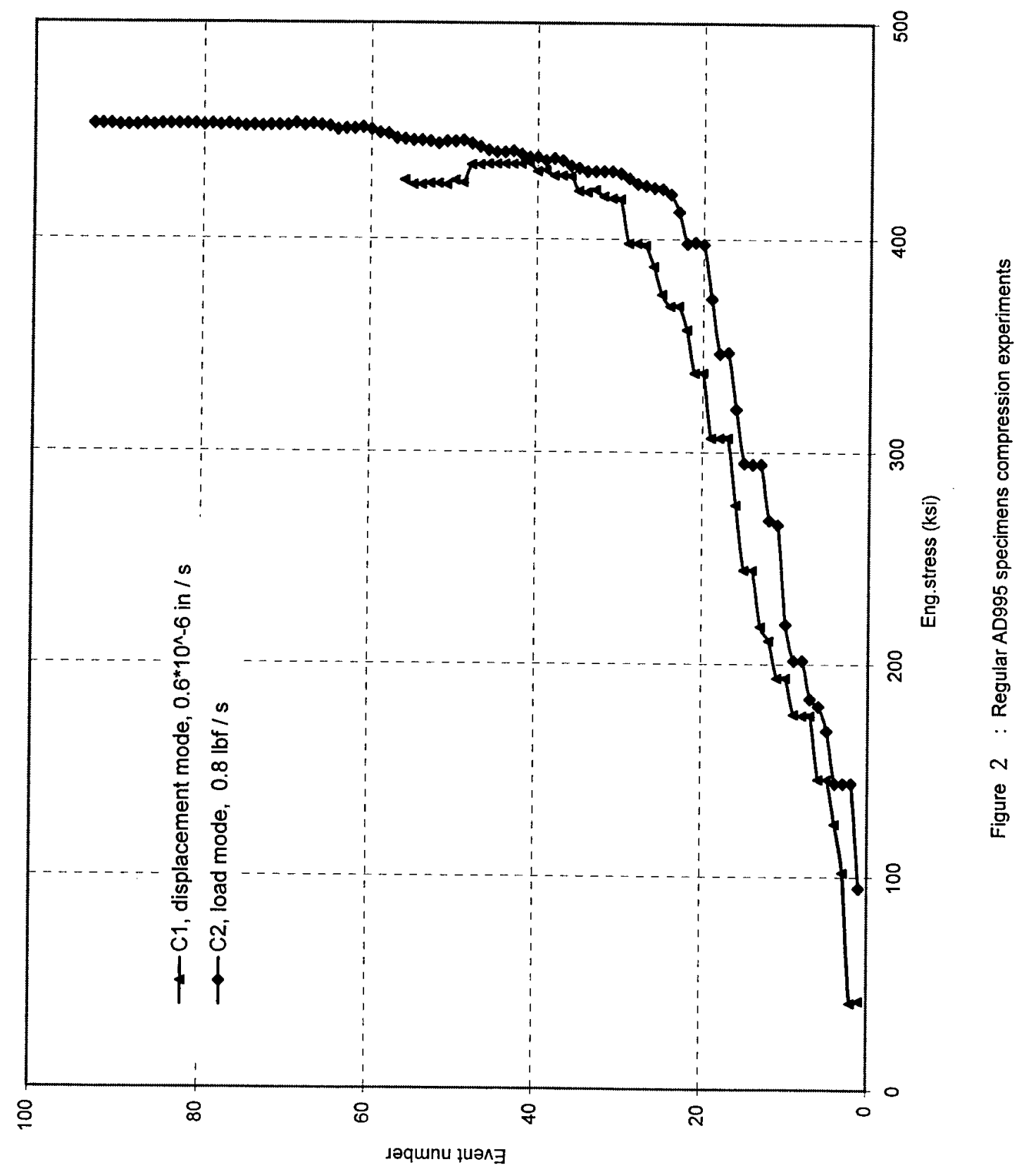




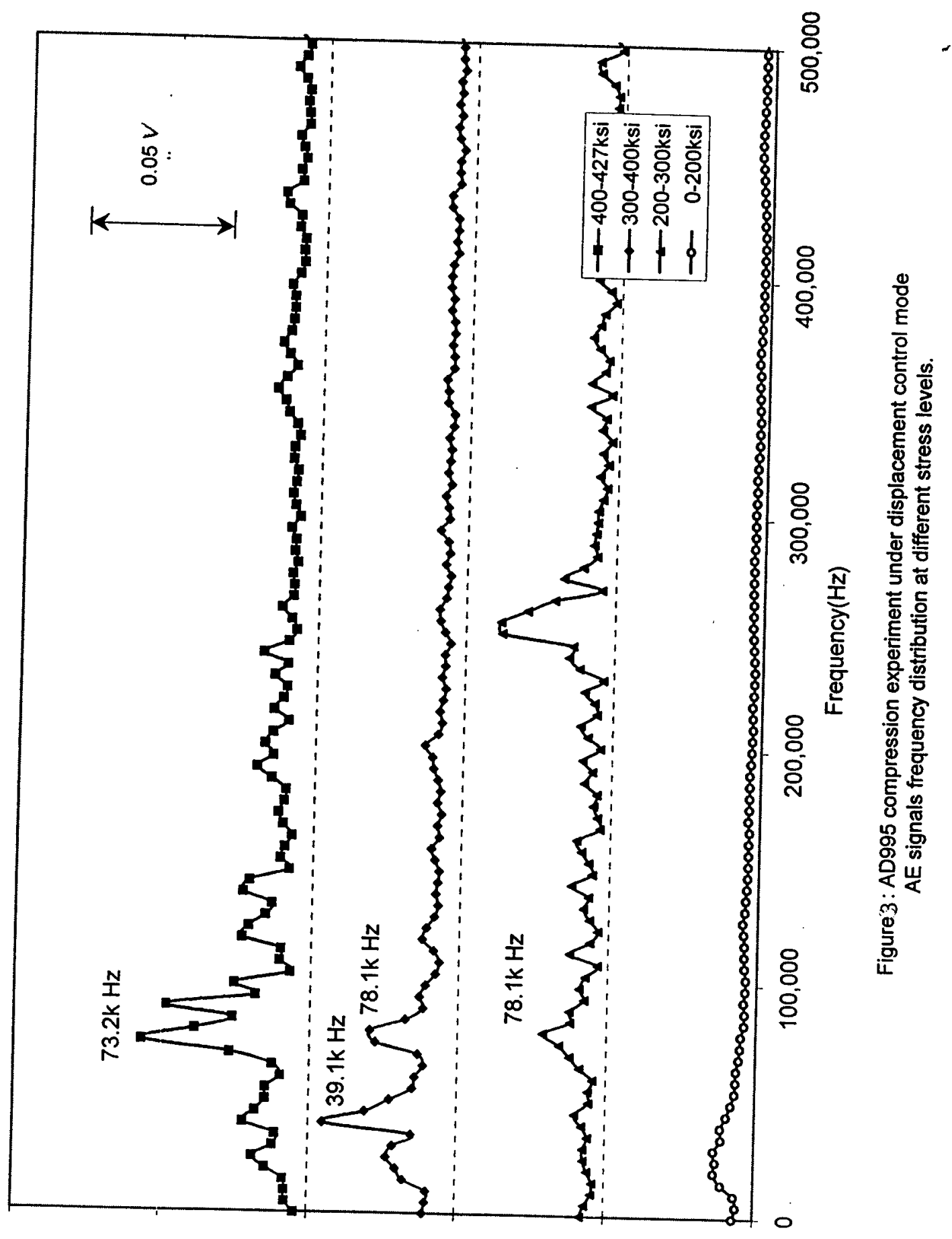

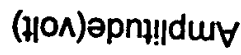




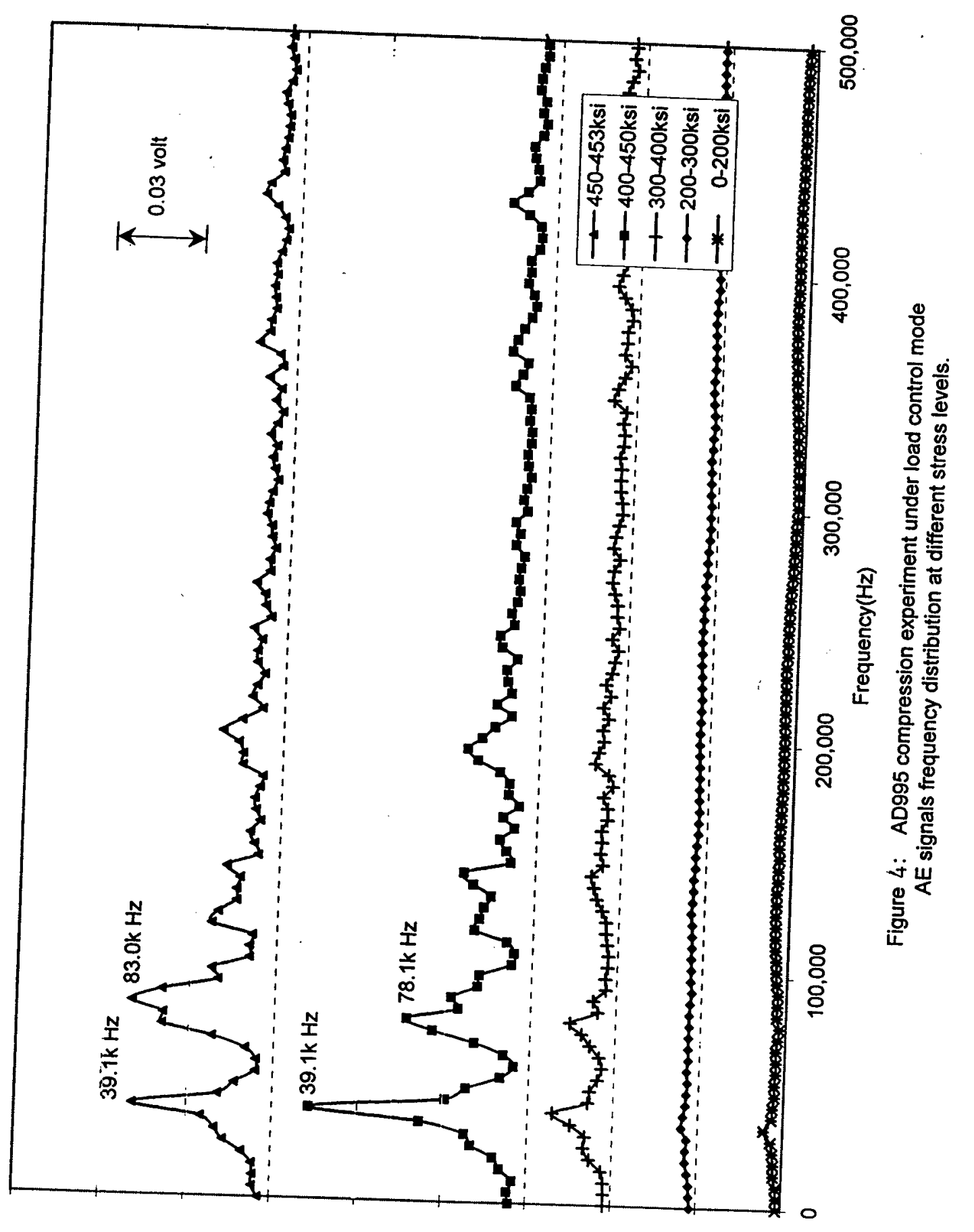

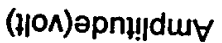




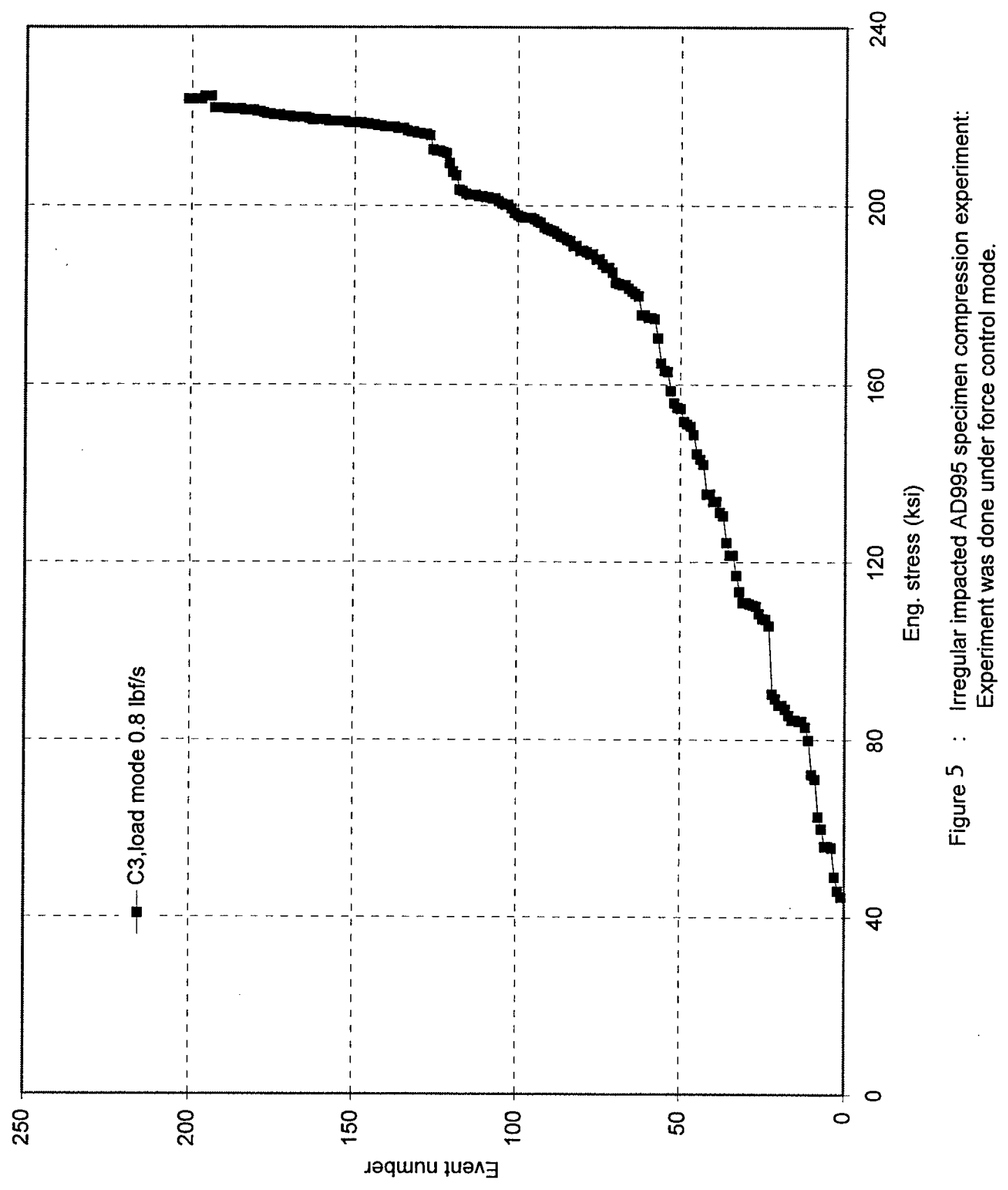




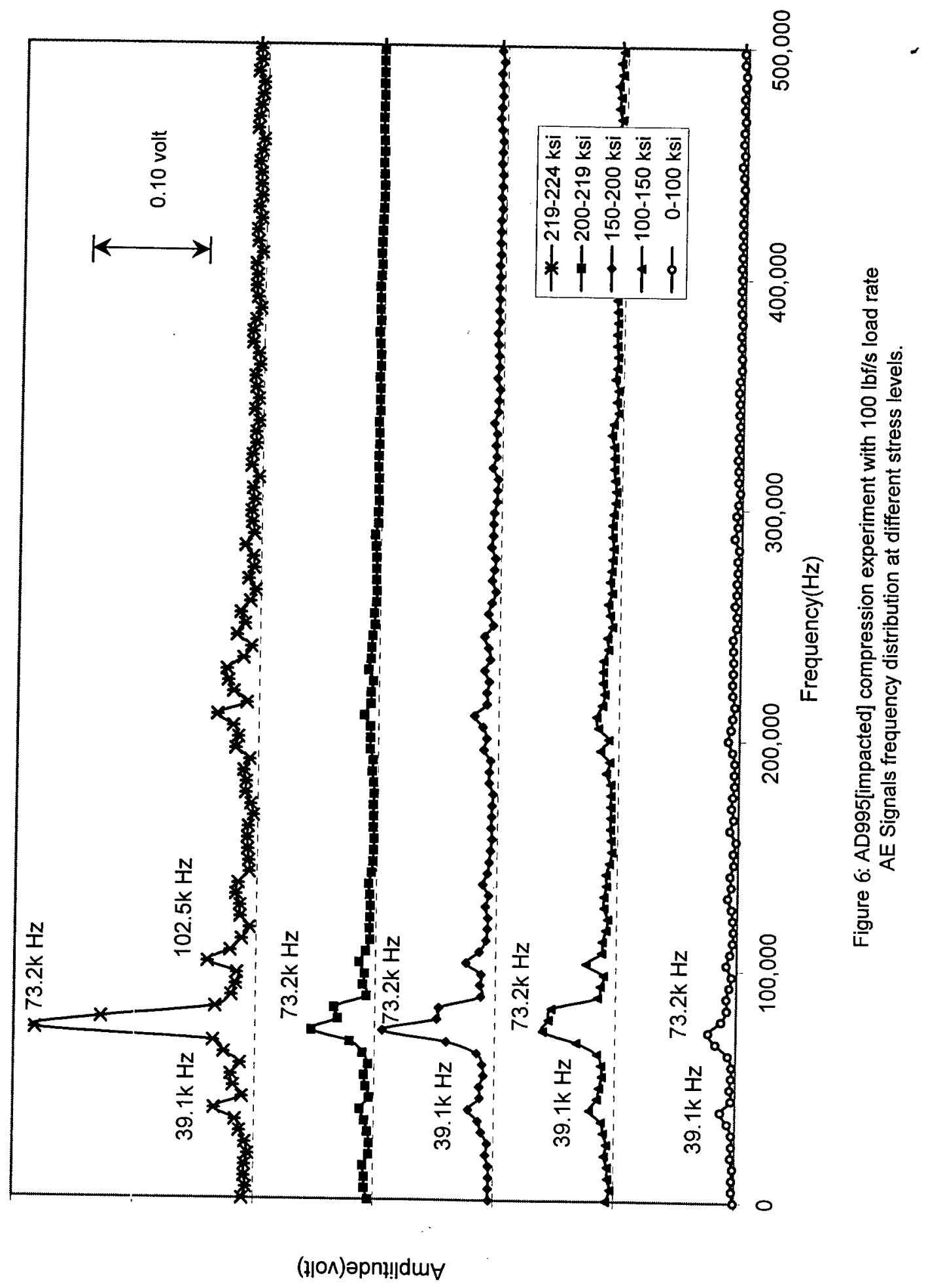




\section{CONCLUSIONS:}

Experiments were performed on Alumina AD 995 under compressive loading at constant displacement rate (strain rate) and load rate (stress rate). Acoustic emission waves were collected using a $35 \mathrm{MHz}$ and 12 bit digitizing system. Each wave was analyzed for frequency contents. It was found that signals which represented damage/crack growth had frequencies between 39 and $80 \mathrm{kHz}$. Further, significant differences were observed in as received 'virgin' material and a shocked material. In the latter case, acoustic emission representing crack growth and multiplication, started at much lower stress and the damage progressed at much faster rate than in the case of un-shocked material. This study established the acoustic emission as a viable technique to monitor damage in ceramic material.

\section{PUBLICATIONS AND REPORTS:}

None

\section{PARTICIPATING SCIENTIFIC PERSONNEL:}

The P.I., Dr. Akhtar S. Khan and a doctoral student, Mr. Shengwen Xu, participated in this project. Mr. Xu is expected to get a doctoral degree in May 2003.

\section{INVENTIONS:}

None

\section{BIBLIOGRAPHY:}

1 Barthelemy, H.M., "Periodic inspection of compressed gas cylinders and transport vessels by using Acoustic Emission testing", Acoustic Emission: Current Practice and Future Directions, ASTM STP 1077, W. Sachse, J. Roget, and K. Yamaguchi, Eds., American Society for Testing and Materials, Philadelphia, 1991.

2 Brockenbrough, J.R. and Suresh, S., "Constitutive behavior of a microcracking brittle solid in cyclic compression”, J. Mech. \& Phys. Solids, 35, p. 721, 1987.

3 Centala, P.K., "Mechanical response and damage in woven S2-glass reinforced polyester under compression: experiments \& modeling”, Ph.D. Dissertation, UMBC 1998.

4 Chhabiladas, L.C., Rajendran, A.M. and Grove, D.J., "Impact of alumina rodsintermediate strain rate experiments", in Constitutive and Damage Modeling of Inelastic Deformation and Phase Transformation, Edited by A.S. Khan, NEAT, Press, Fulton, MD, p. 627, 1999. 
5 Enoki, $\mathrm{M}$. and Kishi, T., "Development and future aspects in AE source Characterization", Acoustic Emission: Current Practice and Future Directions, ASTM STP 1077, W. Sachse, J. Roget, and K. Yamaguchi, Eds., American Society for Testing and Materials, Philadelphia, 1991.

6 Espinosa, H.D. and Brar, N.S., "Dynamic failure mechanisms of ceramic bárs: Experiments and numerical simulations", J. Mech. Phys. Solids, $\underline{43}$, p. 1615, 1995.

7 Grabec, I., Sachse, W. and Govekar, E., "Solving AE problem by a neural network", Acoustic Emission: Current Practice and Future Directions, ASTM STP 1077, W. Sachse, J. Roget, and K. Yamaguchi, Eds., American Society for Testing and Materials, Philadelphia, 1991.

8 Grady, D.E., "Dynamic properties of ceramic materials", SAND 94-32 66, Sandia Nat. Lab., Albuquerque, NM, 1995.

9 Heiple, C.R., Carpenter, S.H. and Christiansen, S.S., "A calibration source for Acoustic Emission analysis", Acoustic Emission: Current Practice and Future Directions, ASTM STP 1077, W. Sachse, J. Roget, and K. Yamaguchi, Eds., American Society for Testing and Materials, Philadelphia, 1991.

10 Higo, Y. and Inaba, H., "The general problems of AE sensor", Acoustic Emission: Current Practice and Future Directions, ASTM STP 1077, W. Sachse, J. Roget, and K. Yamaguchi, Eds., American Society for Testing and Materials, Philadelphia, 1991.

11 Kiernan, M.T. and Duke, J.C., Jr., "Theoretic basis of the Acoustic Ultrasonic method", Acoustic Emission: Current Practice and Future Directions, ASTM STP 1077, W. Sachse, J. Roget, and K. Yamaguchi, Eds., American Society for Testing and Materials, Philadelphia, 1991.

12 Krajcinovic, D. and Fanella, D., "A micromechanical damage model for concrete", Engg. Fracture Mech., 25, p. 585, 1986.

13 Lankford, J., "Temperature-strain rate dependence of compressive strength and damage mechanisms in Aluminum Oxide", J. Mater. Sci., 16, p. 1567, 1981.

14 Louro, L.H.L. and Meyers, M.A., "Effect of stress state and microstructural parameters on impaci damage of alumina-based ceramics, J. Mater. Sci., $\underline{24}$, p. 2516, 1989.

15 McBride, S.L., Pollard, M.D., MacPhail, J.D., Bowman, P.S. and Peters, D.T., "Acoustic emission detection of crack presence and crack advance during flight", Acoustic Emission: Current Practice and Future Directions, ASTM STP 1077, W. Sachse, J. Roget, and K. Yamaguchi, Eds., American Society for Testing and Materials, Philadelphia, 1991.

16 Mori, Y. and Kishil, T., "Relationship between Acoustic Emission and flaw size in Si3N4 ceramics", Acoustic Emission: Current Practice and Future Directions, ASTM STP 1077, W. Sachse, J. Roget, and K. Yamaguchi, Eds., American Society for Testing and Materials, Philadelphia, 1991. 
17 Rajendran, A.M. and Grove, D.J., "Modeling the shock response of Silicon Carbide, Boron Carbide, and Titanium Diboride”, Int. J. Impact Engg., 1996.

18 Rajendran, A.M. and Grove, D.J., "A comparison study of damage evolution using the Rajendran-Grove and Johnson-Holmquist ceramic models", in Constitutive and Damage Modeling of Inelastic Deformation and Phase Transformation, Edited A.S. Khan, NEAT, Press, Fulton, MD, p. 671, 1999.

19 Rajendran, A.M. and Kroupa, J.L., "Impact damage model for ceramic materials", J. App. Phys., 66, p. 3560, 1989.

20 Rosenberg, Z., Yeshurun, Y. and Brandon, D.G., "Dynamic response and microstructure of commercial alumina", J. Physique, 46, p. 331, 1985. 